\title{
Histology, lectin histochemistry and ultrastructure of interdigital gland in crossbred sheep
}

\author{
S. Maya ${ }^{a}$, (D) A.R.Sreeranjini ${ }^{\text {b }}$, (D) C. Leena ${ }^{c}$, (D) N.S.Sunil Kumar ${ }^{c}$, K.B. Sumena ${ }^{c}$ and \\ Irshad, A. ${ }^{\text {d }}$
}

\begin{abstract}
${ }^{a}$ Director, Academic Staff College and Professor and Head, Department of Veterinary Anatomy \& Histology, College of Veterinary and Animal Sciences, Mannuthy, Kerala Veterinary and Animal Sciences University, India

${ }^{b}$ Associate Professor, Department of Veterinary Anatomy \& Histology, College of Veterinary and Animal Sciences, Mannuthy, Kerala Veterinary and Animal Sciences University, India

${ }^{\mathrm{c}}$ Assistant Professor, Department of Veterinary Anatomy \& Histology, College of Veterinary and Animal Sciences, Mannuthy, Kerala Veterinary and Animal Sciences University, India

${ }^{d}$ Centre of Excellence in Meat Science and Technology and Department of Livestock Products Technology, College of Veterinary and Animal Sciences, Mannuthy, Thrissur, Kerala, India
\end{abstract}

Corresponding author: S. Maya|Email: maya@kvasu.ac.in

Co-authors: ARS: sreeranjini@kvasu.ac.in ; CL: leena@kvasu.ac.in ; NSS: sunilkumar@kvasu.ac.in

KBS: sumena@kvasu.ac.in; IA: irshad@kvasu.ac.in

Received: 11-10-2020, Accepted: 24-11-2020, Published online: 20-12-2020

\begin{abstract}
Histology, lectin histochemistry and ultrastructure of interdigital gland in sheep was studied using six adult cross bred sheep of either sex collected from the Meat Technology Unit, College of Veterinary and Animal Sciences, Mannuthy. The manus and pes were detached from the rest of limbs and after recording the gross observations, the interdigital glands were fixed in 10 per cent neutral buffered formalin and processed for histological examinations. Stratified squamous epithelium with a prominent keratin layer lined the lumen, similar to the skin over the dorsal surface of manus and pes. The epidermis presented mucosal folds, which projected into the lumen. The dermis contained small sebaceous glands, hair follicles of different sizes, arrector pili muscles and apocrine sweat glands. The secretory epithelium of sweat glands was lined with a simple layer of cuboidal and relatively flattened cells. The excretory ducts of these glands were lined by cuboidal cells, with darker appearance than its secretory portion. The fibrous capsule was composed of dense connective tissue with collagen, adipose cells, blood vessels and nerve fibers. Glandular secretion and the granules in the stratum granolosum of the surface squamous epithelium showed positive reaction for lectin Ulex europaeus (UEA-I). The apocrine nature of sweat glands was revealed in the ultrastructural studies by scanning electron microscope.
\end{abstract}

Keywords: Interdigital gland, sheep, histology, lectin histochemistry and ultrastructure

doi: https://doi.org/10.51128/jfas.2020.A020 | How to cite this article:S. Maya, Sreeranjini, A.R., Leena, C., Sunilkumar, N. S., Sumena, K. B. and Irshad, A., 2020. Histology, lectin histochemistry and ultrastructure of interdigital gland in crossbred sheep. Journal of Food and Animal Sciences, 01(02): 112 - 116.

Copyright: Maya et al., 2020. Open Access. This article is distributed under the terms of the Creative Commons Attribution 4.0 International License (http://creativecommons.org/licenses/by/4.0/), which permits unrestricted use, distribution, and reproduction in any medium, provided you give appropriate credit to the original author(s) and the source, provide a link to the Creative Commons license, and indicate if changes were made. The Creative Commons Public Domain Dedication waiver (http://creativecommons.org/publicdomain/zero/1.0/) applies to the data made available in this article, unless otherwise stated. 


\section{Introduction}

Scent glands are exocrine glands found in most mammals. They produce semiviscous secretions which contain pheromones and other chemical compounds. These odor-messengers indicate information such as status, territorial marking, mood and sexual power. The odour may be subliminal-not consciously detectable. Though it is not their primary function, the salivary glands may also function as scent glands in some a nimals.

In ungulates or hoofed mammals, the communication of reproductive information is thought to be accomplished by odours associated with cutaneous glands localized to specific areas (Konig and Liebich, 2007). The even-toed ungulates (Artiodactyla) have many specialized skin glands, the secretions of which are involved in semiochemical communication. These glands include the sudoriferous or sweat glands (located on the forehead, between the antlers and eyes), the preorbital glands (extending from the medial canthus of each eye), the nasal glands (located inside the nostrils), the interdigital glands (located between the toes), the preputial gland (located inside the foreskin of the penis), the metatarsal glands (located outside of the hind legs), and the tarsal glands (located inside of the hind legs).

The interdigital glands belong to a group of cutaneous apocrine glands, varied in morphology, located in cleft between the hooves, in several species of Artiodactyla (Abbasi et al., 2009). Also called as the 'hoof skin organ' (Raesfeld, 1978) or interdigital sinus (Bavdek, 1981) or interdigital pouch in sheep (Pourlis, 2010), it is a peculiar tubular invagination of the skin which comprises mainly sebaceous and apocrine type glandular structures. In some species, like sheep and Japanese serow (Atoji et al., 1988), these glands are found interdigitally on both the fore- and hind feet while the roe deer (Capreolus capreolus L.) shows the gland only on the hind feet (Janicki et al., 2003).

In sheep, roe deer and Japanese serow the glandular secreted material is inside a pouch with a hair-covered excreting duct, from which secretion trickles (Sivachelvan et al., 1992), but in other species this gland is merely a form of skin fold (Pocock, 1910). This gland produces the apocrine and holocrine types of secretion where either the apical cytoplasm or the whole cellular content is expelled as secretion respectively. The discharge is an oily substance at various viscosity and composition through a prominent orifice at the anterior aspect of the interdigital cleft. The odorous nature of discharge is used as a trial marker or as sure-footedness by animals. The odorous signals and pheromones produced by these scent glands play essential biological roles in the conspecific chemical messages including active territorial delimitation and in the manifestation of social behavior including breeding. These foot glands may also be related to alternative functions, such as secretion of a waste product or a scent marker to help lost sheep find their flock (Parillo and Diverio, 2009). The present study was carried out to elucidate the gross, histological, lectin histochemical and ultrastructural characteristics of interdigital glands in crossbred sheep.

\section{Materials and Methods}

The study was conducted using six adult cross bred sheep of either sex collected from the Meat Technology Unit, College of Veterinary and Animal Sciences, Mannuthy. The manus and pes were detached from the rest of limbs and after recording the gross observations, the interdigital glands for histological purpose were fixed in 10 per cent neutral buffered formalin (10\% NBF), for 48 hours. The fixed specimens were washed, dehydrated and embedded in high melting paraffin (MP 58$60^{\circ} \mathrm{C}$ ). Serial sections of $5 \mu \mathrm{m}$ thickness were made and stained histologically using Gomori's one step trichrome method for collagen and muscle fibres, Oil Red' O' in propylene glycol method for fat (Luna, 1968), Gomori's alkaline phosphatase cobalt method and Gomori's method for acid phosphatase (Sing and Sulochana, 1996). Digital images were stored in Leica DM 2000 LED microscope. Lectin histochemistry was done using Fluorescein iso-thiocyanate (FITC)conjugated lectin from Ulex europaeus 1 (West et al., 2012) and examined under Fluorescence (Leica DM 2000 LED) microscope with green filter. Samples were fixed in $2.5 \%$ gluteraldehyde in $0.1 \mathrm{M}$ phosphate buffer ( $\mathrm{pH} 7.2$ ) for $24 \mathrm{hrs}$ at $4^{\circ} \mathrm{C}$ and processed for Scanning Electron Microscopy (SEM - Model: JOEL-JSM 5600) as per the standard procedures (Bozzola and Russell, 1998) at Ruska labs, College of Veterinary Science, Hyderabad. 


\section{Results and Discussion}

Grossly, the interdigital glands were tubular invaginations, located between the proximal and middleinterphalangealjoints(Fig. 1)withnodifference between sides, feet or sex. The gland presented a long, narrow neck and a blind sac intervened by an obvious flexure. The dorsal extremity opened on the anterio-dorsal aspect of the proximal interdigital cleft (Fig. 2), while the distal extremity rested against the interdigital ligament (Fig. 1). The gland had a thick capsule and numerous fine hairs were seen on the sagittal surface confirming the earlier reports by Aslan et al. (2010).

Histologically, a thick connective tissue capsule was observed externally (Fig. 3), composed of dense connective tissue with bundles of collagen running in two directions right angles to each other, adipose cells, blood vessels and nerve fibers. Stratified squa mous epithelium with a prominent keratin layer lined the lumen (Fig. 4), similar to the skin over the dorsal surface of manus and pes. The epidermis presented mucosal folds, which projected into the lumen. Underlying dermis contained sebaceous and sweat glands, hair follicles of different sizes and arrector pili muscles.

Glandular parenchyma was represented by the glandular acini and the stroma consisted of the connective tissue. Secretory epithelium of apocrine sweat glands was lined with a single layer of cuboidal and relatively flattened cells. The excretory ducts of these glands were also lined by cuboidal cells, with darker appearance than its secretory portion.

Glandular secretion (Fig. 5) and the granules in the stratum granolosum of the surface squamous epithelium showed positive reaction as green fluorescence for the FITC-conjugated lectin Ulex europaeus 1 (Fig. 4) indicating the presence of $\alpha$ เ- fucose, a glycoconjugate and hence the cellular maturation. The secretion exhibited mild positive reaction for oil Red 'O' (Fig.6) indicating the presence of lipids. A mild acid phosphatase activity was seen in the glandular acini, hair follicles and epidermis, suggestive of the lysosomal activity and the resultant repair (Fig.3). These sites also exhibited mild positive activity for alkaline phosphatase demonstrating the process of ongoing differentiation. The apocrine nature of secretion was evident in scanning electron microscopy (Fig. 7).

The present morphohistological study indicated the presence of a well developed interdigital gland in all the four feet of the crossbred sheep with strongly active secretion. The blood supply ensured by the branches of the $3^{\text {rd }}$ and $4^{\text {th }}$ palmar and dorsal digital arteries, at the respective aspects, were responsible for the nourishment at the forefeet while the sole supply to the interdigital sinuses of the hindfeet were from the $3^{\text {rd }}$ and $4^{\text {th }}$ plantar digital arteries (Aslan et al., 2010). Parillo and Diverio (2009) have demonstrated that the interdigital tubular glands in the fallow deer also secreted neutral glycoproteins, containing hexoses with vicinal hydroxyls, suggesting that the interdigital glands may probably play a role in the production of odoriferous signals in the species.

\section{Authorship contribution statement}

S. Maya: Conceptualization, Writing - original draft, Writing - review \& editing, Visualization, Supervision, A. R. Sreeranjini: Conceptualization, Writing review \& editing. C. Leena: Writing - original draft, Writing - review \& editing. N.S. Sunilkumar: Conceptualization, Methodology, Writing - original draft, Writing - review \& editing. K.B. Sumena: Writing - original draft, Writing - review \& editing. Irshad, A: Conceptualization, Writing - original draft, Writing - review \& editing.

\section{Acknowledgments}

All the authors acknowledge and thank their respective Institutes and Universities.

\section{Funding}

The financial assistance extended by the Animal Husbandry Department, Kerala, India and the administrative help rendered by the Kerala Veterinary and Animal Sciences University in conducting the research are gratefully acknowledged.

\section{Declaration of Competing Interest}

All authors declare that there exist no commercial or financial relationships that could, in any way, lead to a potential conflict of interest. 


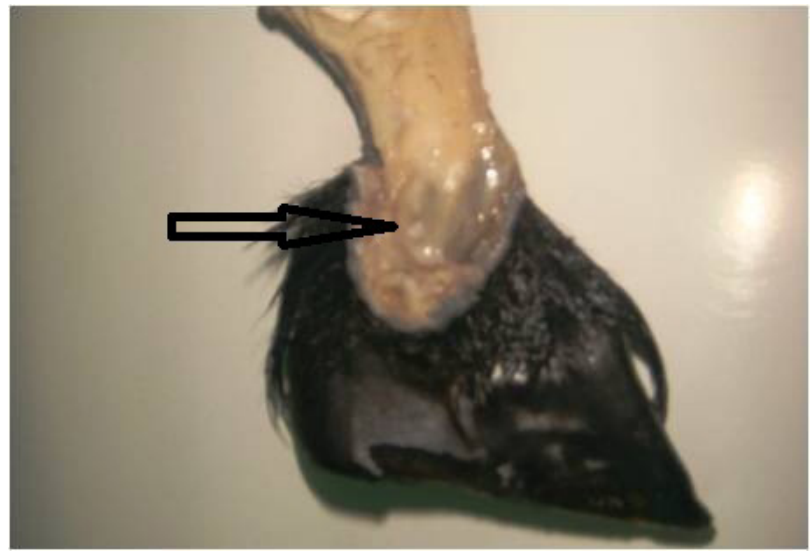

Fig 1. Interdigital gland of adult sheep. Medial view.

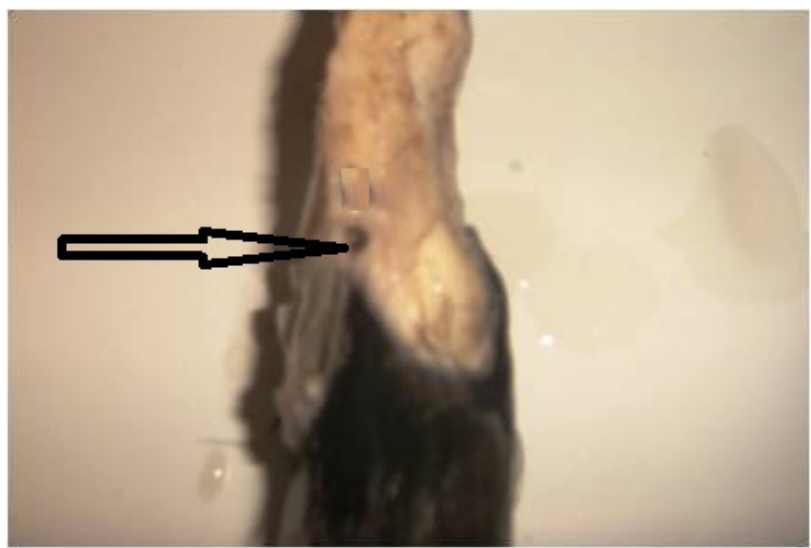

Fig. 2. Opening of Interdigital gland of adult sheep. Dorsal view.

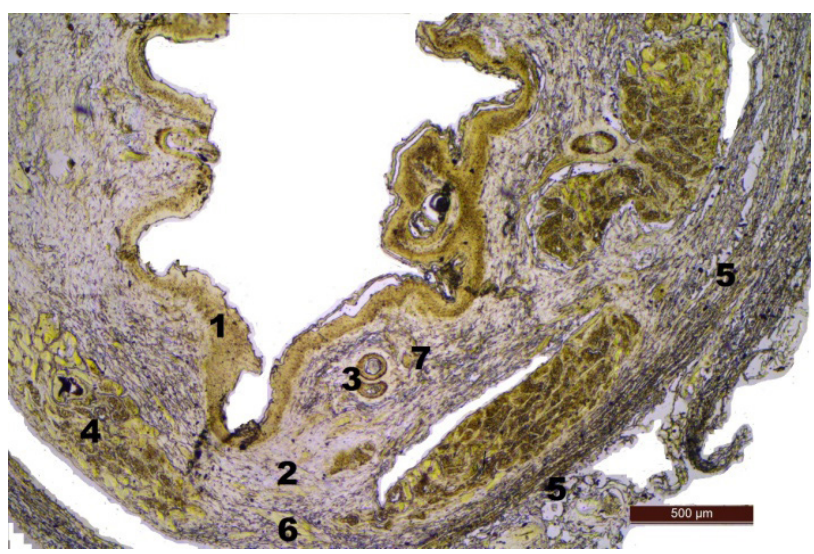

Fig. 3. Interdigital gland of adult sheep exhibiting acid phosphatase activity in the glandular acini, hair follicle and epidermis $\mathrm{x} 100$

\section{Epidermis; $\quad$ 2. Dermis; $\quad 3$. Hair follicles;}

4. Glandular acini; 5. Capsule 6. Arrector pili muscle; 7. Sebaceous glands

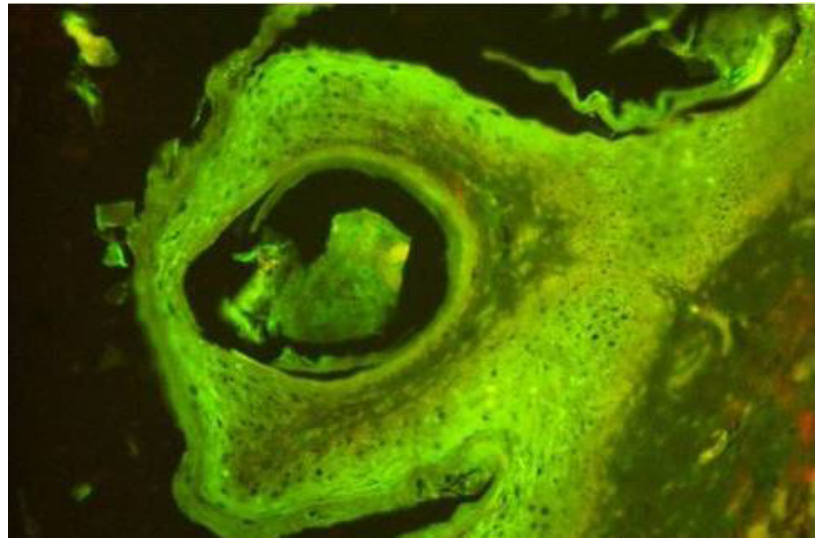

Fig. 4. Stratum granulosum of epidermis in interdigital gland of adult sheep exhibiting positive response as green fluorescence to FITC-conjugated lectin from Ulex europaeus (UEA) x 200

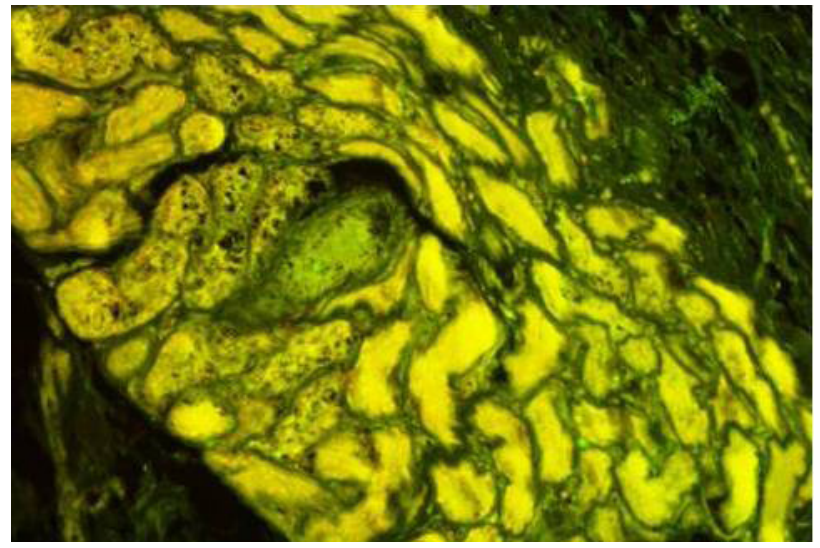

Fig. 5. Interdigital gland of adult sheep exhibiting positive response of green fluorescence to FITCconjugated lectin from Ulex europaeus (UEA) x 100

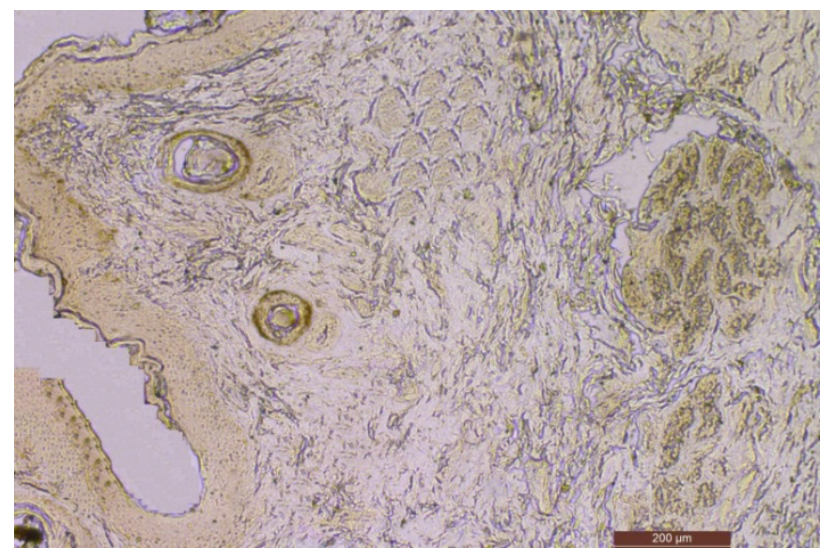

Fig. 6. Interdigital gland of adult sheep exhibiting mild Oil Red 'O' activity in the glandular acini, hair follicle and epidermis $\mathrm{x} 100$ 


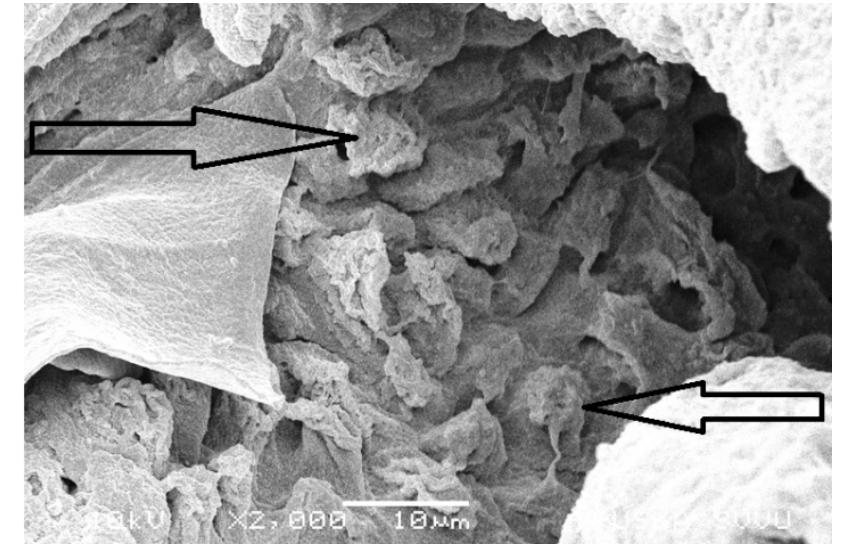

Fig. 7. Glandular duct showing cells with dried up secretions (arrows) on their luminal surface. Scanning Electron Microscopy x 2000

\section{References}

Abbasi , M., Gharzi , A., Mohammadzadeh, S. and Karimi , H. 2009. Morphology and Histology of the Interdigital Gland in an Iranian Native Breed of Sheep. J. Anim. Vet. Advances. 8(6): 1157-1161.

Aslan, K., Kürtül, I., Nazli, M. And Ateş, S. 2010. Morphologic Features of the Interdigital Sinus of the Tuj Sheep. Kafkas Univ Vet Fak Derg. 16 (4): 623-626.

Atoji, Y., M. Sugimura, Y. Suzuki. 1988. Lecitin histochemistry of the interdigital gland in the Japanese serow (Capricornis crispus) in winter. J. Anat. 161: 159า170.

Bavdek, S. 1981: Interdigitalni sinus ovaca. In: Koa in njeni derivati. VTOZD. Biotehniske fakultete $v$ Ljubljani.

Bozzola, J.J. and Russell, L.D. 1998. Electron Microscopy Principles and Techniques for Biologists. ( $2^{\text {nd }}$ Ed.). Jones and Bartlett Pub., Massachusetts. pp.19-
24.

Janicki, Z., A. Hraste, A. Slavica, D. Konjevic, Z. Marinovic, D. Stubican. 2003. Morphohistological characteristics of the interdigital gland in the roebuck (Capreolus capreolus L.). Vet. Arhiv. 73: 27-37.

Konig, H.E. and Leibich (2007). Veterinary Anatomy of Domestic Mammals, Textbook and Colour Atlas. ( ${ }^{\text {rd }}$ Edn). Schattauer Gmbh, Germany, pp: 618. ISBN: 978-3-7945-2485-3.

Luna, L. G. 1968. Manual of Histological Staining Methods of the Armed Forces Institute of Pathology ( ${ }^{\text {rd }}$ Ed.).McGraw-Hill Book Company, New York, 258p.

Parillo, F. and Diverio, S. 2009. Glycocomposition of the apocrine interdigital gland secretions in the fallow deer. Res Vet Sci, 86: 194-199.

Pocock, R. I. 1910. On the specialized cutaneous glands of ruminants. Proceedings of the Zoological Society of London, pp. 840-986.

Pourlis, A.F. 2010. Functional morphological characteristics of the interdigital sinus in the sheep. Folia Morphol (Warsz). 69(2):107-11.

Raesfeld, V. F. 1978. Das Rehwild. Verlag Paul Parey, Ha mburg und Berlin, pp. 10-15.

Singh, U.B. and Sulochana, S. 1996. Hand book of Histological and Histochemical Techniques. Premier Publishing House, Hyderabad, p. 111.

Sivachelvan, M. N., A. Yahaya, A. G. Chibuzo. 1992. Developmental changes in the interdigital pouch of Yankasa sheep. Small Ruminant Res. 9: 303-312.

West, K.P., Patts, H.A., Fletcher, A. and Walker, F. 2012. Tsissue carbohydrate identification by the use of lectins. Technical methods. 177: 239240. 